Nicole Prüfer | Burkhard Kleuser | Markus van der Giet

\title{
The role of serum amyloid A and sphingosine-1-phosphate on high-density lipoprotein functionality
}

Suggested citation referring to the original publication:

Biological Chemistry 396(6-7) (2015), pp. 573-583

DOI http://dx.doi.org/10.1515/hsz-2014-0192

ISSN (print) 1431-6730

ISSN (online) 1437-4315

Postprint archived at the Institutional Repository of the Potsdam University in:

Postprints der Universität Potsdam

Mathematisch-Naturwissenschaftliche Reihe ; 340

ISSN 1866-8372

http://nbn-resolving.de/urn:nbn:de:kobv:517-opus4-398648 



\section{Review}

Nicole Prüfer, Burkhard Kleuser and Markus van der Giet*

\section{The role of serum amyloid $A$ and sphingosine-1-phosphate on high-density lipoprotein functionality}

\begin{abstract}
The high-density lipoprotein (HDL) is one of the most important endogenous cardiovascular protective markers. HDL is an attractive target in the search for new pharmaceutical therapies and in the prevention of cardiovascular events. Some of HDL's anti-atherogenic properties are related to the signaling molecule sphingosine-1-phosphate (S1P), which plays an important role in vascular homeostasis. However, for different patient populations it seems more complicated. Significant changes in HDL's protective potency are reduced under pathologic conditions and HDL might even serve as a proatherogenic particle. Under uremic conditions especially there is a change in the compounds associated with HDL. S1P is reduced and acute phase proteins such as serum amyloid A (SAA) are found to be elevated in HDL. The conversion of HDL in inflammation changes the functional properties of HDL. High amounts of SAA are associated with the occurrence of cardiovascular diseases such as atherosclerosis. SAA has potent pro-atherogenic properties, which may have impact on HDL's biological functions, including cholesterol efflux capacity, antioxidative and anti-inflammatory activities. This review focuses on two molecules that affect the functionality of HDL. The balance between functional and dysfunctional HDL is disturbed after the loss of the protective sphingolipid molecule S1P and the accumulation of the acute-phase protein SAA. This review also summarizes the biological activities of lipid-free and lipid-bound SAA and its impact on HDL function.
\end{abstract}

\footnotetext{
*Corresponding author: Markus van der Giet, Charité Centrum 13, Department of Nephrology, Charité - Universitätsmedizin Berlin, Campus Benjamin Franklin, Hindenburgdamm 30, D-12203 Berlin, Germany, e-mail: Markus.vanderGiet@charite.de Nicole Prüfer: Charité Centrum 13, Department of Nephrology, Charité - Universitätsmedizin Berlin, Campus Benjamin Franklin, Hindenburgdamm 30, D-12203 Berlin, Germany; and MathematischNaturwissenschaftliche Fakultät, Universität Potsdam, D-14476 Potsdam, Germany

Burkhard Kleuser: Mathematisch-Naturwissenschaftliche Fakultät, Universität Potsdam, D-14476 Potsdam, Germany
}

Keywords: atherosclerosis; high-density lipoprotein (HDL); inflammation; serum amyloid A (SAA); sphingosine-1-phosphate (S1P).

DOI 10.1515/hsz-2014-0192

Received April 28, 2014; accepted September 23, 2014; previously published online October 25, 2014

\section{Introduction}

\section{High-density lipoprotein - structure and function}

High-density lipoprotein (HDL) is the smallest and densest of the plasma lipoproteins. HDL exists as a number of subclasses of particles in the plasma, differing in shape, protein and lipid composition, density and size (Barter et al., 2003). HDL is a macromolecular complex of proteins and lipids (a core containing triacylglycerol and cholesteryl ester and, on the surface, cholesterol and phospholipids). The primary apolipoproteins (Apos) in HDL are ApoA-I and Apo-AII, which represent up to $70 \%$ and $20 \%$ of the total HDL protein, respectively. Furthermore, HDL transports many other apolipoproteins, such as ApoA-IV, ApoE, ApoJ and ApoM and enzymes, including paraoxonase (PON), platelet-activating factor acetylhydrolase (PAF-AH), lecithin cholesterol acyltransferase (LCAT), and cholesteryl ester transfer protein. The heterogeneous nature of HDL results from constant remodeling of the particle in response to a range of factors in plasma (Barter, 2002). Under physiological conditions, HDL displays potent antiatherogenic properties. The atheroprotective role of HDL is partially attributed to its role in promoting cholesterol efflux from peripheral tissues (Glomset, 1968). Furthermore, HDL protects against atherosclerosis via multiple other pleiotropic mechanisms (Stein and Stein, 1999; Nofer et al., 2002; Assmann and Nofer, 2003) including anti-inflammatory (Xia et al., 1999), antioxidative (Ng 
et al., 2005), vasodilatory, antithrombotic (Mineo et al., 2006) and antiapoptotic (de Souza et al., 2010) activities. In recent years, some of these protective biological activities of HDL have been related to the sphingolipid sphingosine-1-phosphate (S1P), which is an essential part of HDL.

\section{The imbalance between atheroprotective and proatherogenic molecules}

Our understanding of HDL and its protective effect on atherogenesis has changed dramatically over time. Gordon's Framingham study showed the strong inverse correlation between serum cholesterol (HDL-C) levels and the risk of atherosclerosis (Gordon et al., 1977). Nevertheless, studies in the early 2000s showed that high HDL-C levels do not necessarily induce an anti-atherogenic effect. There is convincing evidence that plasma levels of HDL-C do not reflect the true atheroprotective functions of HDL. It was demonstrated, for example, that HDL concentrations no longer correlated with cardiovascular mortality in dialysis patients (Kilpatrick et al., 2007). Despite this, lipid-modifying therapies aiming to increase HDL levels in patients worked as expected. For example, the treatment of patients with a cholesteryl ester transfer protein inhibitor, such as torcetrapib or dalcetrapib, effectively increased the HDL-C levels in these patients; however this HDL-C increase did not reduce the occurrence of cardiovascular events. On the contrary there was an increase in cardiovascular morbidity and mortality observed (Barter et al., 2007; Schwartz et al., 2009). These results indicate that HDL functionality does not necessarily correlate with HDL-C concentration (HDL quantity). Many patients who experience cardiovascular events have normal or even high levels of HDL-C (Corsetti et al., 2006), which gives the impression that functionality of HDL is important. The molecular structure of HDL is not static, but rather fluid: apolipoproteins can dissociate from HDL particles to interact with cellular structures and subsequently associate with HDL again (Vedhachalam et al., 2010). Recent studies have focused on the loss of antioxidative and antiinflammatory activities of HDL in uremic patients (Jurek et al., 2008; Vaziri et al., 2009). There is decreased activity of anti-inflammatory and antioxidative factors in uremic patients. At the same time there seems to be an increase in substances with proinflammatory capacity in these patients. It has been shown that structural alterations in HDL occur under inflammatory conditions. Sattler and coworkers showed that in patients with coronary artery disease, HDL looses functionality associated with a loss of S1P (Sattler et al., 2010). In systemic inflammatory response syndrome and sepsis, apolipoproteins such as ApoM are reduced (Kumaraswamy et al., 2012). In addition, our results revealed decreased S1P levels in HDL from patients with end-stage renal disease (ESRD) compared to healthy controls (unpublished data). In contrast, proinflammatory factors, such as serum amyloid A (SAA), can accumulate in HDL. SAA itself acts as a proinflammatory active substance. Figure 1 shows the structural changes in HDL during an acute phase response. The current review summarizes the knowledge relating to how S1P associated with HDL is an atheroprotective player and how SAA acts as a proinflammatory substance potentially counteracting the functions of S1P. Both substances play a substantial role in HDL's functionality. In this review we focus on the function of S1P associated with HDL particles, which is distinct from S1P's actions when not bound to HDL. The differences have been extensively reviewed in Schuchardt et al. (2011).

\section{Sphingosine-1-phosphate: an atheroprotective player associated with HDL}

S1P has been identified as a bioactive signaling molecule that modulates several cell functions, including cell proliferation, differentiation and migration (Olivera and Spiegel, 1993; Lee et al., 1998, 1999). In addition to a de novo pathway, S1P can be formed via the degradation of sphingomyelin, a eukaryote-specific plasma membrane lipid that is essential for the arrangement of caveolae and lipid rafts. Sphingomyelin can be metabolized by sphingomyelinases leading to the formation of ceramide (Hannun and Obeid, 2008). Ceramidases are the predominant enzymes that degrade ceramides, yielding the free sphingoid base sphingosine, which can be phosphorylated by sphingosine kinases (SphK), resulting in the formation of S1P. Two isoforms of SphK have been discovered, which are referred to as type 1 and 2; Sphk1 is localized to the cytoplasm, whereas Sphk2 is primarily located in the nuclei (Ogawa et al., 2003; Venkataraman et al., 2006). The S1P levels in plasma and tissue are tightly regulated by the equilibrium between its synthesis and degradation. The degradation of S1P is regulated by both specific and nonspecific phosphate phosphohydrolases (SPP1, SPP2 and LPP3), which hydrolyze S1P to sphingosine, or by the S1P-lyase, which cleaves S1P into hexadecenal and phosphoethanolamine (Le Stunff et al., 2002; Ogawa et al., 2003).

The performance of various S1P-mediated functions is facilitated by either the modulation of the intracellular functions of S1P or the activity of the sphingolipid as a ligand of G-protein-coupled receptors after its secretion 


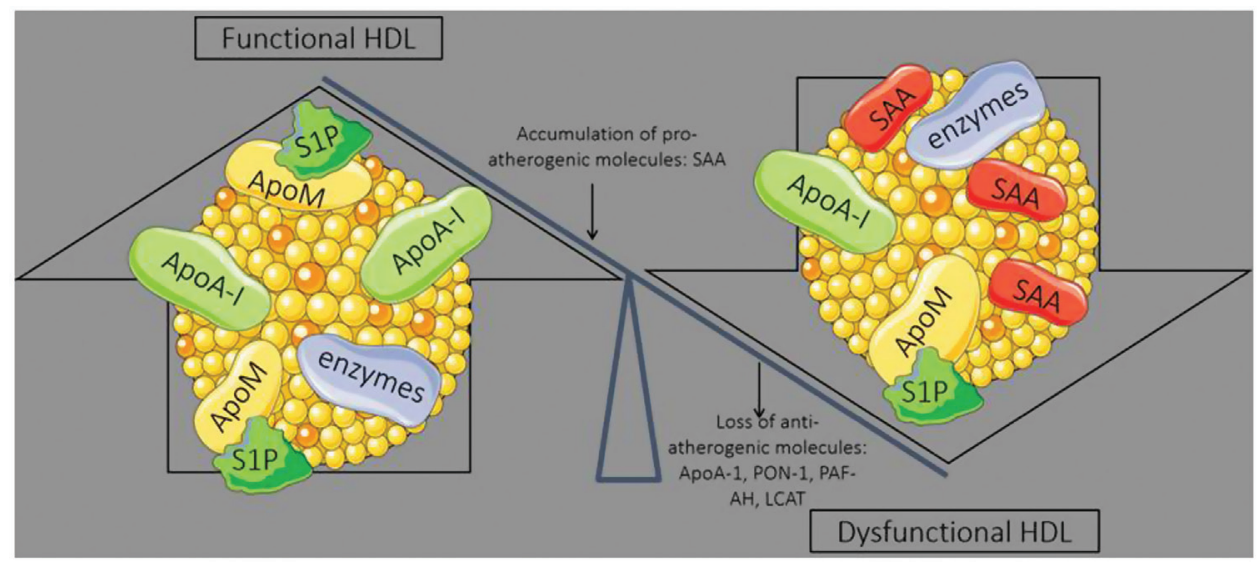

Figure 1 Structural changes in HDL under acute phase response.

Normal functional HDL contains apolipoproteins, lipids and antioxidative enzymes. During acute phase response, the accumulation of proatherogenic molecules such as SAA and the loss of antiatherogenic molecules like ApoA-I, PON-1, PAF-AH, LCAT, ApoM and S1P creates dysfunctional HDL. Abbreviations: Apo: apolipoprotein; LCAT: Lecithin cholesterol acyltransferase; PAF-AH: platelet-activating factor acetylhydrolase; PON-1: paraoxonase 1; SAA: serum amyloid A; S1P: sphingosine-1-phosphate.

into the extracellular environment. Currently, five receptors for S1P, termed S1P1-S1P5, have been identified, and these receptors display tissue-selective expression patterns (Chun et al., 2002; Blaho and Hla, 2011).

In mammalian organisms S1P is primarily present in the blood, whereas levels are generally low in the tissues. There is an S1P gradient between the lymphoid organs, which contain low S1P levels, and lymph and blood, which contain high S1P concentrations. This gradient directs the chemotactic egress of lymphocytes from lymphoid tissues toward the blood or the lymph.

The concentration of S1P in plasma varies between $200 \mathrm{~nm}$ and $1000 \mathrm{~nm}$, and due to its amphiphilic characteristic most of the S1P in plasma is bound to proteins. Indeed, approximately $55 \%$ of the total S1P is transported via HDL, whereas $36 \%$ of S1P is bound to albumin (Murata et al., 2000). Only a minor portion of S1P is transported by other lipoproteins, such as very low-density lipoprotein and low-density lipoprotein (LDL). It has been suggested that some of the biological functions of HDL are related to the activity of HDLassociated S1P. Thus, the anti-inflammatory properties of HDL and HDL-associated S1P are explained by its ability to inhibit diapedesis by selectively decreasing the expression of endothelial adhesion molecules, which facilitate the binding of mononuclear cells to the vessel wall. Moreover, the integrity of blood vessels is critical for vascular homeostasis, and disruption of endothelial barrier function is detected under pathophysiological conditions, such as hemorrhage, edema and inflammation. S1P binding to HDL therefore appears to be a crucial factor in enhancing barrier integrity through its therapeutic potency. In addition, S1P plays a role in renal diseases (reviewed in Koch et al., 2013). S1P that is not bound to HDL has some other actions with proinflammatory signaling, i.e., activating intracellular adhesion molecule or vascular cell adhesion molecule. These unbound S1P actions are reviewed in Schuchardt et al. (2011). However, the question remains as to why most of the S1P is bound to HDL. The enigma may be explained by the finding of a direct interaction between S1P and the lipoprotein ApoM. ApoM is a $25-\mathrm{kDa}$ protein that is primarily coupled to HDL via a specific hydrophobic signal peptide (Christoffersen et al., 2011). Indeed, more than 95\% of the ApoM present in plasma is associated with HDL. Only a minor portion is associated with LDL and very low-density lipoprotein (Christoffersen et al., 2011). The essential role of ApoM as a transport protein of S1P is demonstrated in ApoM-deficient mice. These S1P level in the plasma of such mice is approximately $46 \%$ lower than in wild-type mice. Moreover, S1P is not detected in HDL from ApoM ${ }^{-}-$mice. Consistent with these findings, the S1P levels in plasma are drastically enhanced when ApoM expression is increased. These data indicate that ApoM is the predominant S1P carrier protein in HDL. It has been considered that the effect of HDL-associated S1P on endothelial barrier function is mediated by specific $\mathrm{G}_{\mathrm{i}}$-coupled S1P receptor subtypes and the Akt signaling pathway (Argraves et al., 2008). In addition, S1P is recognized as a crucial molecule in HDL that is primarily responsible for the vasodilatory effect of HDL in isolated aortae ex vivo (Nofer et al., 2004). 
It has been shown that HDL-induced vasodilatation is due to the formation of nitric oxide (NO), an atheroprotective signaling molecule. HDL-associated S1P is responsible for the formation of NO because it up-regulates endothelial NO synthase after stimulation of the S1P3 receptor. Nofer et al. showed this when the effect of HDL on vascular dilation was examined in S1P3-deficient mice. HDL almost completely lost its ability to induce vasodilation in the absence of the S1P3 receptor subtype. Additionally, the scavenger receptor $\mathrm{BI}$ is recognized as a crucial receptor in HDL-induced vasodilation (Nofer et al., 2004). S1P protects endothelial cells (ECs) from apoptosis via the inhibition of caspases and the formation of NO (Kwon et al., 2001). Furthermore, it has been shown that S1Pbound HDL inhibits the NAD(P)H oxidase-dependent synthesis of thrombin-induced monocyte chemoattractant protein-1 (MCP-1), the key regulatory chemokine in monocyte recruitment during atherogenesis (Tolle et al., 2008).

It has been suggested that regulation of the endothelial barrier by protein-bound S1P depends on the type of carrier. For example, Wilkerson et al. elucidated that the effect of HDL-S1P on endothelial barrier function is more extensive than that of S1P bound to albumin (Wilkerson et al., 2012). Thus, it can be concluded that HDL-bound S1P, which is chaperoned by ApoM, promotes the interaction between S1P and its receptor (Christoffersen et al., 2011). Indeed, it has been shown that S1P/S1P1R signaling is prolonged when S1P is bound to HDL. The S1P1 receptor has recently been crystallized (Hanson et al., 2012), and it will be interesting to examine the structural characteristics that promote the interaction between ApoMchaperoned S1P and the binding site of the S1P1 receptor. The complex interplay between HDL, S1P and ApoM is also demonstrated in ApoM-deficient mice. These mice are characterized by not only decreased S1P plasma levels but also increased vascular leakage into the lungs (Christoffersen et al., 2011). These data demonstrate the fundamental roles of HDL-bound S1P and its association with HDL-specific ApoM. This understanding is of potential interest in the development of therapeutic applications for diseases such as atherosclerosis or sepsis, in which endothelial barrier function is heavily dysregulated.

\section{Serum amyloid A: a proatherogenic acting molecule}

The acute phase protein SAA is associated with the occurrence of cardiovascular disease and atherosclerosis (Dong et al., 2011; King et al., 2011). The structure of SAA was reported in the early 1980 s. The SAA protein family is encoded by four genes that are found in various species, including humans and mice. Only three of these genes are commonly expressed in humans, however, resulting in three protein isoforms: SAA1, SAA2 and SAA4.

SAA is highly conserved. It is predominantly expressed in the liver but is also expressed by cells of the artery wall, including monocytes/macrophages (Urieli-Shoval et al., 1994), ECs, vascular smooth muscle cells (VSMCs) and adipocytes (Meek et al., 1994). During an acute phase response, SAA1 and SAA2 (A-SAA) are highly expressed in the liver. They are induced by the pro-inflammatory cytokine interleukin (IL)-1, IL-6 and tumor necrosis factor alpha (TNF- $\alpha$ ). In contrast, SAA4 (C-SAA) is constitutively expressed in the liver and is not regulated by inflammatory responses.

SAA1, the gene for which is located on chromosome 11, consists of 104 amino acids with a molecular weight of $12 \mathrm{kDa}$ and is the predominant member of the SAA family. HDL is the major carrier of SAA1 in human plasma (Marhaug and Husby, 1982). It does not exist in a free form, and associates with non-HDL lipoproteins in the absence of HDL (Cabana et al., 2004). SAA1 binds to HDL via its $\mathrm{N}$-terminal domain (Liang et al., 1996); and residues 1-11 of SAA1, which form an alpha-helical structure, are critical for its interaction with lipids (Ohta et al., 2009). The circulating levels of SAA2 can be increased up to 1000 -fold during an acute phase response (Malle et al., 1993). Under physiological conditions, SAA2 levels range between $2 \mu \mathrm{g} /$ $\mathrm{ml}$ and $5 \mu \mathrm{g} / \mathrm{ml}$ (Malle et al., 1993).

During an acute phase response, SAA becomes the primary apolipoprotein in HDL, displacing apo-A1 (Coetzee et al., 1986). During acute inflammation, SAA can account for up to $80 \%$ of the total protein content (Cabana et al., 1989). Structural alterations can significantly change the protective function of HDL and convert HDL into a proatherogenic particle. SAA accumulation in HDL may be responsible for the loss of HDL's antiatherogenic function, SAA itself acting as a proinflammatory molecule. The proatherogenic properties of SAA may affect HDL function. HDL-associated SAA may convert functional antiatherogenic HDL into dysfunctional proatherogenic HDL. SAA has various biological functions in the vascular system, including the regulation of immune cell migration (Badolato et al., 1994) and the stimulation of inflammatory factor production (Patel et al., 1998). It has been demonstrated that SAA is present in both mouse (Qiao et al., 1994) and human atherosclerotic lesions (Meek et al., 1994; Yamada et al., 1996). SAA induces cytokine production in THP-1 cells (Patel et al., 1998), macrophages (Song et al., 2009a,b), VSMCs (Tolle et al., 2012), and EC lines (Lakota et al., 2013). In addition, SAA increases 
tissue factor activity and TNF- $\alpha$ levels in THP-1 cells (Song et al., 2009a,b). Exposure of ECs to SAA induces the production of proinflammatory and prothrombotic factors (Wang et al., 2008). Recombinant human SAA1/2 induces the expression of matrix metalloproteinases (MMPs) that degrade the extracellular matrix of fibroblasts and monocytes in vitro (Migita et al., 1998; Lee et al., 2005). Recombinant SAA also induces foam cell formation in macrophages (Lee et al., 2013a,b) and enhances sPLA2 secretion in VSMCs (Sullivan et al., 2010). Furthermore, SAA induces reactive oxygen species production and the proliferation of fibroblasts (Hatanaka et al., 2011). It has also been shown that SAA directly affects the vascular endothelium. Recombinant SAA1/2 up-regulates the production of cell adhesion molecules in ECs (Witting et al., 2011). The exposure of human aortic ECs to SAA decreases NO synthesis and stimulates superoxide $\left(\mathrm{O}_{2}^{-}\right)$production. SAA also diminishes the relaxation of preconstricted aortic rings induced by acetylcholine (Witting et al., 2011). These biological functions of SAA may promote the development of atherosclerosis and may contribute to HDL dysfunction.

\section{Serum amyloid $A$ and its impact on HDL dysfunction}

SAA-enrichment in HDL may impair the atheroprotective activities of HDL, including its cholesterol efflux capacity and its anti-inflammatory, antioxidative and cytoprotective functions. Table 1 summarizes the protein and lipid components that are involved in the biological activities of HDL and the impact of SAA on HDL function. During an acute phase response, HDL displays diminished antioxidative and anti-inflammatory properties, which may even be transformed into pro-oxidative and proinflammatory activities (Van Lenten et al., 1995). The HDL particle content of native, nonmodified ApoA-I is significantly decreased in hypercholesterolemic subjects (Yang et al., 2005), whereas that of SAA is enriched in these patients. In addition, SAA is elevated in patients with metabolic syndrome (MedinaUrrutia et al., 2008). During an acute phase response, SAA replaces ApoA-I in HDL particles (Coetzee et al., 1986), and the ApoA-I plasma levels are reduced (Cabana et al., 1996). In addition, patients with coronary heart disease exhibit significantly decreased ApoA-I levels and significantly increased SAA levels in HDL compared with healthy individuals (Wang et al., 2013).

\section{Serum amyloid $A$ and its effect on reverse cholesterol efflux}

ApoA-I plays a major role in cellular cholesterol efflux (Ohta et al., 1992) and ApoA-I replacement by SAA significantly affects the reverse cholesterol efflux. Enrichment of HDL with SAA to $86 \%$ of total protein content results in decreased efflux capacity and increased cholesteryl ester uptake by macrophages (Banka et al., 1995; Artl et al., 2000). Despite this, moderate enrichment of HDL with SAA to $27 \%$ of total protein in vivo does not influence the cholesterol efflux capacity of HDL, but enhances the

Table 1 HDL components involved in HDL functional activities and the role of serum amyloid A (SAA).

\begin{tabular}{lll}
\hline Component & Biologic activity & Role of SAA \\
\hline $\begin{array}{l}\text { ApoA-I (interaction with ABCA1 and ABCG1 } \\
\text { transporters and scavenger receptor B1) } \uparrow\end{array}$ & Cholesterol efflux & $\begin{array}{l}\text { Replacement by SAA } \\
\text { In macrophages } \uparrow \\
\text { In hepatocytes } \downarrow\end{array}$ \\
$\begin{array}{l}\text { ApoA-I (reduction of lipid hydroperoxides, } \\
\text { scavenging ROS) } \uparrow, \text { ApoA-IV, ApoE, ApoM (removal } \\
\text { of oxLDL from cells, scavenging ROS) } \uparrow\end{array}$ & Anti-oxidative \\
$\begin{array}{l}\text { PON-1, PAF-AH, LCAT (hydrolysis of short-chain } \\
\text { oxidized PLs) } \uparrow\end{array}$ & & $\begin{array}{l}\text { Replacement by SAA? } \\
\text { ApoA-I (removal of pro-inflammatory oxLDL } \\
\text { from cells) } \uparrow \text { PON-1, PAF-AH (hydrolysis of pro- } \\
\text { inflammatory oxidized phospholipids) } \uparrow\end{array}$ \\
$\begin{array}{l}\text { ApoA-1 and sphingosine-1-phosphate (inhibition of } \\
\text { adhesion molecules on endothelial cells, inhibition } \\
\text { of apoptosis induced by oxLDL) } \uparrow\end{array}$ & Anti-inflammatory \\
\hline $\begin{array}{l}\uparrow \\
\text { f }\end{array}$ & & \\
\end{tabular}

$\uparrow$, up-regulates biological activity of HDL; $\downarrow$, down-regulates biological activity of HDL; Apo, apolipoprotein; ABCG1, ATP-binding cassette transporter G1; ABCA1, ATP-binding cassette transporter A1; LCAT, Lecithin cholesterol acyltransferase; oxLDL, oxidized low-density lipoprotein; PON-1, paraoxonase 1; PAF-AH, platelet-activating factor acetylhydrolase; ROS, reactive oxygen species. 
binding of HDL to macrophages (Banka et al., 1995). The cholesterol efflux capacity can be impaired during inflammation and the acute phase response (McGillicuddy et al., 2009; Annema et al., 2010). SAA overexpression in mice significantly contributes to reduced macrophage-to-feces reverse cholesterol efflux (Annema et al., 2010). It appears that SAA promotes cholesterol efflux by macrophages (Stonik et al., 2004; van der Westhuyzen et al., 2005) but reduces lipid uptake by hepatocytes (Kisilevsky and Subrahmanyan, 1992; Artl et al., 2002; Cai et al., 2005). It has also been shown that mouse SAA2 and SAA2 fragments promote cholesterol efflux from macrophages in vitro and in vivo (Tam et al., 2002; Kisilevsky and Tam, 2003).

One group of investigators recently analyzed the effect of SAA on cellular cholesterol efflux in type 2 diabetes mellitus patients because type 2 diabetes is associated with inflammation. The investigators found that the SAA levels were significantly increased in these patients. Both the scavenger receptor B1 and ABCG1 cholesterol efflux activities to serum were significantly impaired. It was shown that the SAA level inversely correlated to scavenger receptor B1-mediated cholesterol efflux to serum (Tsun et al., 2013).

Another study showed that inflammation impairs steps in reverse cholesterol efflux (de Beer et al., 2013). This study revealed that in lipopolysaccharide-injected mice, the transfer of labeled cholesterol from macrophages to plasma was reduced in both in wild type and SAA knock-out mice, indicating that SAA plays only a minor role in this activity.

\section{Serum amyloid $A$ and its effect on HDL's anti- oxidative activity}

During the induction of an acute phase response, HDL loses its ability to protect against LDL oxidation due to decreased PON-1 and PAF-AH activities (Watson et al., 1995a,b). PON-1 is a major antiatherosclerotic component in HDL. It is possible that, on the one hand, oxidative modifications of HDL are responsible for the decreased PON-1 activity. On the other hand, SAA incorporation during the inflammatory response, resulting in the replacement of several enzymes, including PON-1, PAF-AH and LCAT, with SAA, may lead to a reduced capacity to inhibit LDL oxidation (Van Lenten et al., 2001). In chronic diseases inflammation and oxidative stress occur together (Khansari et al., 2009) and collectively change HDL particles into proatherogenic particles by decreasing PON-1 content and increasing SAA content. Several clinical studies have analyzed the correlation between SAA levels and PON-1 activity. In patients with rheumatoid arthritis, the ratio of PON-1 to SAA was reduced (Tanimoto et al., 2003) and PON-1 activity was decreased. Another study showed a significant inverse correlation between PON-1 activity and SAA levels in patients with metabolic syndrome (Kappelle et al., 2011). Experimental studies have shown that PON-1 mRNA expression is decreased in human hepatoma HepG2 cells due to stimulation with the inflammatory cytokines IL-1B and TNF- $\alpha$ but not due to stimulation with SAA (Kumon et al., 2002). Other experimental studies have shown that PON-1 activity could be displaced from HDL in vitro by incubating serum with recombinant human or murine SAA. This displacement occurs more strongly in murine HDL than in rabbit HDL, but it does not occur in human HDL (Cabana et al., 2003).

\section{Serum amyloid $A$ and its effect on HDL's anti-inflammatory activity}

The major mechanisms underlying the functional alterations in HDL during acute phase response most likely include the replacement of ApoA-I with SAA (Van Lenten et al., 2001). The reduction of HDL ApoA-I levels in inflammatory conditions is related to both decreased hepatic ApoA-I synthesis and the replacement of ApoA-I with SAA in HDL particles (Le Goff et al., 2004). The impaired inactivation of proinflammatory oxidized phospholipids is in agreement with the depletion of ApoA-I in HDL during an acute phase response. The formation of proinflammatory HDL correlates with decreased activities of HDL-associated enzymes, including PON-1, PAF-AH and LCAT, which are replaced with SAA during the acute phase response. HDL from ESRD patients displays a lower anti-inflammatory capacity in the inhibition of monocyte chemotactic activity in cultured human aortic ECs than HDL from control subjects (Vaziri et al., 2009). In addition, the results of our studies revealed that HDL from ESRD patients displays decreased anti-inflammatory activity and decreased the potential to inhibit thrombin-activated MCP-1 production in rat VSMCs. Moreover, the HDL from dialysis patients displays a proinflammatory capacity that correlates with the accumulation of SAA in HDL (Tolle et al., 2012). Interestingly, this process may represent the mechanism by which SAA activates MCP-1 production in these cells, which is currently under investigation. There are several receptors that bind to SAA, including Toll-like receptor 2 (Cheng et al., 2008; He et al., 2009) and Toll-like receptor 4 (Sandri et al., 2008), formyl peptide receptor-like 1 (Lee et al., 2010), CD36 (Baranova et al., 2010), receptor for advanced glycation endproducts, $\mathrm{P} 2 \mathrm{X}_{7}$ (Christenson et al., 
2008; Niemi et al., 2011) and scavenger receptor B1 (Mullan et al., 2010). How SAA could activate such a diverse group of receptors remains under investigation. Weichhart et al. showed that under uremic conditions HDL becomes proinflammatory by accumulating SAA (Weichhart et al., 2012). In addition, the HDL from renal dysfunction patients on hemodialysis and peritoneal dialysis, who are characterized by the presence of dyslipidemia, is less effective in reducing vascular cell adhesion protein 1 expression in ECs than HDL from control subjects (Jurek et al., 2008). These structural alterations in HDL, as well as the related functional changes, may at least partially explain the elevated cardiovascular risk in patients with chronic kidney disease.

\section{Conclusions}

Several studies have shown that it is not the amount of HDL, but rather the quality of HDL that is important. A high level of HDL does not necessarily decrease the risk of cardiovascular events. S1P association with HDL has been identified as important in the mediation of many beneficial functions of HDL, but to date only one clinical study has examined the S1P levels in HDL from patients with coronary heart disease. In contrast to S1P, the acute phase protein SAA disrupts various biological functions of HDL, including its cholesterol efflux capacity and its antioxidative and anti-inflammatory activities. SAA has also been associated with cardiovascular disease and atherosclerosis. Recombinant SAA is a powerful proatherogenic factor. SAA counteracts the function of S1P when associated with HDL. It must be clarified whether HDL-associated SAA contributes to vascular morbidity and mortality under pathological conditions. It is particularly necessary to evaluate whether HDL-associated SAA is proatherogenic due to the replacement of anti-inflammatory and antioxidative enzymes with SAA.

There is a need to evaluate the levels of S1P and SAA in HDL from different patient populations associated with cardiovascular risk based on epidemiological or clinical studies. Such studies are needed to clarify whether alterations in the levels of S1P and SAA participate in HDL dysfunction. In addition, animal models and in vitro studies would help us understand the underlying mechanisms of HDL dysfunction. SAA could serve not only as a potential diagnostic biomarker of inflammatory disease but also as a therapeutic target against inflammation for the prevention of cardiovascular events. In the clinic, plasma levels of SAA can be determined easily and routinely, for example using enzyme-linked immunosorbent assays or Luminex ${ }^{\mathrm{TM}}$ assays. A more challenging barrier is the removal of SAA from the blood circulation.

Acknowledgments: We acknowledge the financial support provided by the Deutsche Forschungsgemeinschaft and the Else Kröner Fresenius Stiftung.

\section{References}

Annema, W., Nijstad, N., Tolle, M., de Boer, J.F., Buijs, R.V., Heeringa, P., van der Giet, M., and Tietge, U.J., (2010). Myeloperoxidase and serum amyloid A contribute to impaired in vivo reverse cholesterol transport during the acute phase response but not group iia secretory phospholipase a(2). J. Lipid. Res. 51, 743-754.

Argraves, K.M., Gazzolo, P.J., Groh, E.M., Wilkerson, B.A., Matsuura, B.S., Twal, W.O., Hammad, S.M., and Argraves, W.S. (2008). High density lipoprotein-associated sphingosine 1-phosphate promotes endothelial barrier function. J. Biol. Chem. 283, 25074-25081.

Artl, A., Marsche, G., Lestavel, S., Sattler, W., and Malle, E. (2000). Role of serum amyloid A during metabolism of acute-phase HDL by macrophages. Arterioscler Thromb. Vasc. Biol. 20, 763-772.

Artl, A., Marsche, G., Pussinen, P., Knipping, G., Sattler, W., and Malle, E. (2002). Impaired capacity of acute-phase high density lipoprotein particles to deliver cholesteryl ester to the human huh-7 hepatoma cell line. Int. J. Biochem. Cell Biol. 34, 370-381.

Assmann, G. and Nofer, J.R. (2003). Atheroprotective effects of highdensity lipoproteins. Ann. Rev. Med. 54, 321-341.

Badolato, R., Wang, J.M., Murphy, W.J., Lloyd, A.R., Michiel, D.F., Bausserman, L.L., Kelvin, D.J., and Oppenheim, J.J. (1994). Serum amyloid $A$ is a chemoattractant: Induction of migration, adhesion, and tissue infiltration of monocytes and polymorphonuclear leukocytes. J. Exp. Med. 180, 203-209.

Banka, C.L., Yuan, T., de Beer, M.C., Kindy, M., Curtiss, L.K., and de Beer, F.C. (1995). Serum amyloid A (SAA): influence on HDL-mediated cellular cholesterol efflux. J. Lipid. Res. 36, 1058-1065.

Baranova, I.N., Bocharov, A.V., Vishnyakova, T.G., Kurlander, R., Chen, Z., Fu, D., Arias, I.M. Csako, G., Patterson, A.P., and Eggerman, T.L. (2010). Cd36 is a novel serum amyloid A (SAA) receptor mediating saa binding and saa-induced signaling in human and rodent cells. J. Biol. Chem. 285, 8492-8506.

Barter, P.J. (2002). Hugh Sinclair lecture: the regulation and remodelling of HDL by plasma factors. Atherosclerosis (Suppl.) 3, 39-47.

Barter, P., Kastelein, J., Nunn, A., and Hobbs, R. (2003). High density lipoproteins (HDLs) and atherosclerosis; the unanswered questions. Atherosclerosis 168, 195-211.

Barter, P.J., Caulfield, M., Eriksson, M., Grundy, S.M., Kastelein, J.J., Komajda, M., Lopez-Sendon, J., Mosca, M., Tardif, J.C., and Waters, D.D. (2007). Effects of torcetrapib in patients at high risk for coronary events. N. Engl. J. Med. 357, 2109-2122. 
Blaho, V.A. and Hla, T. (2011). Regulation of mammalian physiology, development, and disease by the sphingosine 1-phosphate and lysophosphatidic acid receptors. Chem. Rev. 111, 6299-6320.

Cabana, V.G., Siegel, J.N., and Sabesin, S.M. (1989). Effects of the acute phase response on the concentration and density distribution of plasma lipids and apolipoproteins. J. Lipid Res. 30, 39-49.

Cabana, V.G., Lukens, J.R., Rice, K.S., Hawkins, T.J., and Getz, G.S. (1996). HDL content and composition in acute phase response in three species: triglyceride enrichment of HDL a factor in its decrease. J. Lipid Res. 37, 2662-2674.

Cabana, V.G., Reardon, C.A., Feng, N., Neath, S., Lukens, J., and Getz, G.S. (2003). Serum paraoxonase: effect of the apolipoprotein composition of hdl and the acute phase response. J. Lipid Res. 44, 780-792.

Cabana, V.G., Feng, N., Reardon, C.A., Lukens, J., Webb, N.R., de Beer, F.C., and Getz, G.S. (2004). Influence of ApoA-i and ApoE on the formation of serum amyloid A-containing lipoproteins in vivo and in vitro. J. Lipid Res. 45, 317-325.

Cai, L., de Beer, M.C., de Beer, F.C., and van der Westhuyzen, D.R. (2005). Serum amyloid $A$ is a ligand for scavenger receptor class $b$ type $i$ and inhibits high density lipoprotein binding and selective lipid uptake. J. Biol. Chem. 280, 2954-2961.

Cheng, N., He, R., Tia, J., Ye, P.P., and Ye, R.D. (2008). Cutting edge: Tlr2 is a functional receptor for acute-phase serum amyloid $A$. J. Immunol. 181, 22-26.

Christenson, K., Bjorkman, L., Tangemo, C., and Bylund, J. (2008). Serum amyloid $A$ inhibits apoptosis of human neutrophils via a $2 \times 7$-sensitive pathway independent of formyl peptide receptor-like 1. J. Leukoc. Biol. 83, 139-148.

Christoffersen, C., Obinata, H., Kumaraswamy, S.B., Galvani, S., Ahnstrom, J., Sevvana, M., Egerer-Sieber, C., Muller, Y.A., Hla, T., Nielsen, L.B., et al. (2011). Endothelium-protective sphingosine-1-phosphate provided by hdl-associated apolipoprotein M. Proc. Natl. Acad. Sci. USA 108, 9613-9618.

Chun, J., Goetzl, E.J., Hla, T., Igarashi, Y., Lynch, K.R., Moolenaar, W. Moolenaar, Pyne, S., and Tigyi, G. (2002). International union of pharmacology. XXXIV. Lysophospholipid receptor nomenclature. Pharmacol. Rev. 54, 265-269.

Coetzee, G.A., Strachan, A.F., van der Westhuyzen, D.R., Hoppe, H.C., Jeenah, M.S., and de Beer, F.C. (1986). Serum amyloid A-containing human high density lipoprotein 3. Density, size, and apolipoprotein composition. J. Biol. Chem. 261, 96449651.

Corsetti, J.P., Zareba, W., Moss, A.J., Rainwater, D.L., and Sparks, C.E. (2006). Elevated HDL is a risk factor for recurrent coronary events in a subgroup of non-diabetic postinfarction patients with hypercholesterolemia and inflammation. Atherosclerosis 187, 191-197.

de Beer, M.C., Wroblewski, J.M., Noffsinger, V.P., Ji, A., Meyer, J.M., van der Westhuyzen, D.R., de Beer, F.C., and Webb, N.R. (2013). The impairment of macrophage-to-feces reverse cholesterol transport during inflammation does not depend on serum amyloid A. J. Lipids 2013, 283-486.

de Souza, J.A., vindis, C., Negre-Salvayre, A., Rye, K.A., Couturier, K.A., Therond, P., Chantepie, S. Salvayre, R., Chapman, M.J., and Kontush, A. (2010). Small, dense HDL 3 particles attenuate apoptosis in endothelial cells: pivotal role of apolipoprotein A-I. J. Cell Mol. Med. 14, 608-620.
Dong, Z., Wu, T., Qin, W., An, C., Wang, Z., Zhang, M., Zhang, Y., Zhang, C., and An, F. (2011). Serum amyloid A directly accelerates the progression of atherosclerosis in apolipoprotein E-deficient mice. Mol. Med. 17, 1357-1364.

Glomset, J.A. (1968). The plasma lecithins: Cholesterol acyltransferase reaction. J. Lipid Res. 9, 155-167.

Gordon, T., Castelli, W.P., Hjortland, M.C., Kannel, W.B., and Dawber, T.R. (1977). High density lipoprotein as a protective factor against coronary heart disease. The Framingham study. Am. J. Med. 62, 707-714.

Hannun, Y.A. and Obeid, L.M. (2008). Principles of bioactive lipid signalling: lessons from sphingolipids. Nat. Rev. Mol. Cell Biol. 9, 139-150.

Hanson, M.A., Roth, C.B., Jo, E., Griffith, M.T., Scott, F.L., Reingart, G., Desale, H., Clemons, B., Cahalan, S.M., Schuerer, S.C., et al. (2012). Crystal structure of a lipid g protein-coupled receptor. Science 335, 851-855.

Hatanaka, E., Dermargos, A., Armelin, H.A., Curi, R., and Campa, A. (2011). Serum amyloid A induces reactive oxygen species (ROS) production and proliferation of fibroblast. Clin. Exp. Immunol. 163, 362-367.

He, R.L., Zhou, J., Hanson, C.Z., Chen, J., Cheng, N., and Ye, R.D. (2009). Serum amyloid A induces $\gamma$-CSF expression and neutrophilia via toll-like receptor 2 . Blood 113, 429-437.

Jurek, A., Turyna, B., Kubit, K., and Klein, A. (2008). The ability of HDL to inhibit VCAM-1 expression and oxidized LDL uptake is impaired in renal patients. Clin. Biochem. 41, 1015-1018.

Kappelle, P.J., Bijzet, J., Hazenberg, B.P., and Dullaart, R.P. (2011). Lower serum paraoxonase- 1 activity is related to higher serum amyloid A levels in metabolic syndrome. Arch. Med. Res. 42, 219-225.

Khansari, N., Shakiba, Y., and Mahmoudi, M. (2009). Chronic inflammation and oxidative stress as a major cause of age-related diseases and cancer. Recent Pat. Inflamm. Allergy. Drug Discov. 3, 73-80.

Kilpatrick, R.D., McAllister, C.J., Kovesdy, C.P., Derose, S.F., Kopple, J.D., and Kalantar-Zadeh, K. (2007). Association between serum lipids and survival in hemodialysis patients and impact of race. J. Am. Soc. Nephrol. 18, 293-303.

King, V.L., Thompson, J., and Tannock, L.R. (2011). Serum amyloid A in atherosclerosis. Curr. Opin. Lipidol. 22, 302-307.

Kisilevsky, R. and Subrahmanyan, L. (1992). Serum amyloid A changes high density lipoprotein's cellular affinity. A clue to serum amyloid A's principal function. Lab. Invest. 66, 778-785.

Kisilevsky, R. and Tam, S.P. (2003). Macrophage cholesterol efflux and the active domains of serum amyloid A 2.1. J. Lipid Res. 44, 2257-2269.

Koch, A., Pfeilschifter, J., and Huwiler, A. (2013). Sphingosine 1-phosphate in renal diseases. Cellular Physiology and Biochemistry $31,745-760$.

Kumaraswamy, S.B., Linder, A., Akesson, P., and Dahlback, B. (2012). Decreased plasma concentrations of apolipoprotein $\mathrm{m}$ in sepsis and systemic inflammatory response syndromes. Crit. Care 16, R60.

Kumon, Y., Nakauchi, Y., Suehiro, T., Shiinoki, T., Tanimoto, N., Inoue, M., Nakamura, T. Hashimoto, K., and Sipe, J.D. (2002). Proinflammatory cytokines but not acute phase serum amyloid A or C-reactive protein, downregulate paraoxonase 1 (pon1) expression by HepG 2 cells. Amyloid 9, 160-164. 
Kwon, Y.G., Min, J.K., Kim, K.M., Lee, D.J., Billar, T.R., and Kim, Y.M. (2001). Sphingosine 1-phosphate protects human umbilical vein endothelial cells from serum-deprived apoptosis by nitric oxide production. J. Biol. Chem. 276, 10627-10633.

Lakota, K., Mrak-Poljsak, K., Bozic, B., Tomsic, M., and Sodin-Semrl, S. (2013). Serum amyloid A activation of human coronary artery endothelial cells exhibits a neutrophil promoting molecular profile. Microvasc, Res, 90, 55-63.

Le Goff, W., Guerin, M., and Chapman, M.J. (2004). Pharmacological modulation of cholesteryl ester transfer protein, a new therapeutic target in atherogenic dyslipidemia. Pharmacol. Ther. 101, 17-38.

Le Stunff, H., Peterson, C., Thornton, R. Milstein, S., Mandala, S.M., and Spiegel, S. (2002). Characterization of murine sphingosine-1-phosphate phosphohydrolase. J. Biol. Chem. 277, 8920-8927.

Lee, M.J., Van Brocklyn, J.R., Thangada, S., Liu, C.H., Hand, A.R., Menzeleev, R., Spiegel, S., and Hla, T. (1998). Sphingosine1-phosphate as a ligand for the $G$ protein-coupled receptor Edg-1. Science 279, 1552-1555.

Lee, M.J., Thangada, S., Claffey, K.P., Ancellin, N., Liu, C.H., Kluk, M., Volpi, M., Sha'afi, R.I., and Hla, T. (1999). Vascular endothelial cell adherens junction assembly and morphogenesis induced by sphingosine-1-phosphate. Cell 99, 301-312.

Lee, H.Y., Kim, M.K., Park, K.S., Bae, Y.H., Yun, J., Park, J.I., Kwak, J.Y., and Bae, Y.S. (2005). Serum amyloid A stimulates matrixmetalloproteinase- 9 upregulation via formyl peptide receptor like-1-mediated signaling in human monocytic cells. Biochem. Biophys. Res. Commun. 330, 989-998.

Lee, H.Y., Kim, S.D., Shim, J.W., Kim, H.J., Yun, J., Baek, S.H., Kim, K., and Bae, Y.S. (2010). A pertussis toxin sensitive G-proteinindependent pathway is involved in serum amyloid $A$-induced formyl peptide receptor 2-mediated Ccl2 production. Exp. Mol. Med. 42, 302-309.

Lee, H.Y., Kim, S.D., Baek, S.H., Choi, J.H., Cho, K.H., Zabel, B.A., and Bae, Y.S. (2013a). Serum amyloid A stimulates macrophage foam cell formation via lectin-like oxidized low-density lipoprotein receptor 1 upregulation. Biochem. Biophys. Res. Commun 433, 18-23.

Lee, H.Y., Kim, S.D., Baek, S.H., Choi, J.H., and Bae, Y.S. (2013b). Role of formyl peptide receptor 2 on the serum amyloid A-induced macrophage foam cell formation. Biochem. Biophys. Res. Commun. 433, 255-259.

Liang, J.S., Schreiber, B.M., Salmona, M., Phillip, G., Gonnerman, W.A., de Beer F.C., and Sipe, J.D. (1996). Amino terminal region of acute phase, but not constitutive, serum amyloid A (ApoSAA) specifically binds and transports cholesterol into aortic smooth muscle and HepG2 cells. J. Lipid Res. 37, 2109-2116.

Malle, E., Steinmetz, A., and Raynes, J.G. (1993). Serum amyloid A (SAA): an acute phase protein and apolipoprotein. Atherosclerosis $102,131-146$.

Marhaug, G. and Husby, G. (1982). Serum amyloid A protein in high density lipoprotein fraction of human acute phase serum. Lancet 2, 1463.

McGillicuddy, F.C., de la Llera Moya, M., Hinkle, C.C., Joshi, M.R., Chiquoine, E.H., Billheimer, J.T., Rothblat, G.H., and Reilly, M.P. (2009). Inflammation impairs reverse cholesterol transport in vivo. Circulation 119, 1135-1145.

Medina-Urrutia, A., Juarez-Rojas, J.G., Martinez-Alvarado, R., Jorge-Galarza, E., Posadas-Sanchez, R., Cardoso-Saldana, G.,
Caracas-Portilla, N., Mendoza-Perez, E., and Posadas-Romero, C. (2008). High-density lipoprotein subclasses distribution and composition in Mexican adolescents with low HDL cholesterol and/or high triglyceride concentrations, and its association with insulin and C-reactive protein. Atherosclerosis 201, 392-397.

Meek, R.L., Urieli-Shoval, S., and Benditt, E.P. (1994). Expression of apolipoprotein serum amyloid A mRNA in human atherosclerotic lesions and cultured vascular cells: implications for serum amyloid A function. Proc. Natl. Acad. USA 91, 3186-3190.

Migita, K., Kawabe, Y., Tominaga, M., Origuchi, T., Aoyagi, T., and Eguchi, K. (1998). Serum amyloid A protein induces production of matrix metalloproteinases by human synovial fibroblasts. Lab. Invest. 78, 535-539.

Mineo, C., Deguchi, H., Griffin, J.H., and Shaul, P.W. (2006). Endothelial and antithrombotic actions of HDL. Circ. Res. 98, 1352-1364.

Mullan, R.H., McCormick, J., Connolly, M., Bresnihan, B., Veale, D.J., and Fearon, U. (2010). A role for the high-density lipoprotein receptor sr-b1 in synovial inflammation via serum amyloid-A. Am. J. Pathol. 176, 1999-2008.

Murata, N., Sato, K., Kon, J., Tomura, H., Yanagita, M., Kuwabara, A., Ui, M., and Okajima, F. (2000). Interaction of sphingosine 1-phosphate with plasma components, including lipoproteins, regulates the lipid receptor-mediated actions. Biochem. J. 352 Pt 3, 809-815.

Ng, C.J., Shih, D.M., Hama, S.Y., Villa, N., Navab, M., and Reddy, S.T. (2005). The paraoxonase gene family and atherosclerosis. Free Radic. Biol. Med. 38, 153-163.

Niemi, K., Teirila, L., Lappalainen, J., Rajamaki, K., Baumann, M.H., Oorni, K., Wolff, H., Kovanen, P.T., Matikainen, S., and Eklund, K.K. (2011). Serum amyloid A activates the nlrp3 inflammasome via $\mathrm{p} 2 \times 7$ receptor and a cathepsin B-sensitive pathway. J. Immunol. 186, 6119-6128.

Nofer, J.R., Kehrel, B., Fobker, M., Levkau, B., Assmann, G., and von Eckardstein, A. (2002). HDL and arteriosclerosis: beyond reverse cholesterol transport. Atherosclerosis 161, 1-16.

Nofer, J.R., van der Giet, M., Tolle, M., Wolinska, I., von Wnuck Lipinski, K., Baba, H.A., Tietge, U.J., Godecke, A., Ishii, I., Kleuser, B., et al. (2004). HDL induces NO-dependent vasorelaxation via the lysophospholipid receptor S1P3. J. Clin. Invest. $113,569-581$

Ogawa, C., Kihara, A., Gokoh, M., and Igarashi, Y. (2003). Identification and characterization of a novel human sphingosine1-phosphate phosphohydrolase, Hspp2. J. Biol. Chem. 278, 1268-1272.

Ohta, T., Nakamura, R., Ikeda, Y., Shinohara, M., Miyazaki, A., Horiuchi, S., and Matsuda, I. (1992). Differential effect of subspecies of lipoprotein containing apolipoprotein A-I on cholesterol efflux from cholesterol-loaded macrophages: functional correlation with lecithin:cholesterol acyltransferase. Biochim. Biophys. Acta 1165, 119-128.

Ohta, S., Tanaka, M., Sakakura, K., Kawakami, T., Aimoto, S., and Saito, H. (2009). Defining lipid-binding regions of human serum amyloid $A$ using its fragment peptides. Chem. Phys. Lipids 162, 62-68.

Olivera, A. and Spiegel, S. (1993). Sphingosine-1-phosphate as second messenger in cell proliferation induced by PDGF and FCS mitogens. Nature 365, 557-560. 
Patel, H., Fellowes, R., Coade, S., and Woo, P. (1998). Human serum amyloid A has cytokine-like properties. Scand. J. Immunol. 48, 410-418.

Qiao, J.H., Xie, P.Z., Fishbein, M.C., Kreuzer, J., Drake, T.A., Demer, L.L., and Lusis, A.J. (1994). Pathology of atheromatous lesions in inbred and genetically engineered mice. Genetic determination of arterial calcification. Arterioscler Thromb. 14, 1480-1497.

Sandri, S., Rodriguez, D., Gomes, E., Monteiro, H.P., Russo, M., and Campa, A. (2008). Is serum amyloid A an endogenous Tlr4 agonist? J. Leukoc. Biol. 83, 1174-1180.

Sattler, K.J., Elbasan, S., Keul, P., Elter-Schulz, M., Bode, C., Graler, M.H., Brocker-Preuss, M., Budde, T., Erbel, T., Heusch, G., et al. (2010). Sphingosine 1-phosphate levels in plasma and HDL are altered in coronary artery disease. Basic Res. Cardiol. 105, 821-832.

Schuchardt, M., Tölle M., Prüfer, J., and van der Giet, M. (2011). Pharmacological relevance and potential of phingosine 1-phosphate in the vascular system. Br. J. Pharmacol. 162, 1140-1162.

Schwartz, G.G., Olsson. A.G., Ballantyne, C.M., Barter, P.J., Holme, I.M., Kallend, D., Leiter, L.A., Leitersdorf, E., McMurray, J.J., Shah, J.J., et al. (2009). Rationale and design of the dal-outcomes trial: efficacy and safety of dalcetrapib in patients with recent acute coronary syndrome. Am. Heart J. 158, 896-901 e893.

Song, C., Shen, Y., Yamen, Y., Hsu, K., Yan, W., Witting, P.K., Geczy, C.L., and Freedman, S.B. (2009a). Serum amyloid A may potentiate prothrombotic and proinflammatory events in acute coronary syndromes. Atherosclerosis 202, 596-604.

Song, C., Hsu, K., Yamen, E., Yan, E., Fock, J., Witting, P.K., Geczy, P.K., and Freedman, S.B. (2009b). Serum amyloid A induction of cytokines in monocytes/macrophages and lymphocytes. Atherosclerosis 207, 374-383.

Stein, O. and Stein, Y. (1999). Atheroprotective mechanisms of HDL. Atherosclerosis 144, 285-301.

Stonik, J.A., Remaley, A.T., Demosky, S.J., Neufeld, E.B., Bocharov, A., and Brewer, H.B. (2004). Serum amyloid a promotes abca1dependent and abca1-independent lipid efflux from cells. Biochem. Biophys. Res. Commun. 321, 936-941.

Sullivan, C.P., Seidl, S.E., Rich, C.B., Raymondjean, M., and Schreiber, M. (2010). Secretory phospholipase A2, group iia is a novel serum amyloid $A$ target gene: activation of smooth muscle cell expression by an interleukin-1 receptor-independent mechanism. J. Biol. Chem. 285, 565-575.

Tam, S.P., Flexman, A., Hulme, J., and Kisilevsky, R. (2002). Promoting export of macrophage cholesterol: the physiological role of a major acute-phase protein, serum amyloid A 2.1. J. Lipid Res. 43, 1410-1420.

Tanimoto, N., Kumon, Y., Suehiro, T., Ohkubo, S., Ikeda, Y., Nishiya, K., and Hashimoto, K. (2003). Serum paraoxonase activity decreases in rheumatoid arthritis. Life Sci. 72, 2877-2885.

Tolle, M., Pawlak, A., Schuchardt, M., Kawamura, A., Tietge, U.J., Lorkowski, S., Keul, P., Assmann, P., Chun, P., Levkau, B., et al. (2008). HDL-associated lysosphingolipids inhibit NAD(P)H oxidase-dependent monocyte chemoattractant protein-1 production. Arterioscler Thromb. Vasc. Biol. 28, 1542-1548.

Tolle, M., Huang, T., Schuchardt, T., Jankowski, T., Prufer, T., Jankowski, J., Tietge, U.J., Zidek, W., and van der Giet, M. (2012). High-density lipoprotein loses its anti-inflammatory capacity by accumulation of pro-inflammatory-serum amyloid A. Cardiovasc. Res. 94, 154-162.
Tsun, J.G., Shiu, S.W., Wong, S.W., Yung, S., Chan, S., and Tan, K.C. (2013). Impact of serum amyloid A on cellular cholesterol efflux to serum in type 2 diabetes mellitus. Atherosclerosis 231, 405-410.

Urieli-Shoval, S., Meek, R.L., Hanson, R.H., Eriksen, N., and Benditt, N. (1994). Human serum amyloid $A$ genes are expressed in monocyte/macrophage cell lines. Am. J. Pathol. 145, 650-660. van der Westhuyzen, D.R., Cai, L., de Beer, M.C., and de Beer, F.C. (2005). Serum amyloid A promotes cholesterol efflux mediated by scavenger receptor B-I. J. Biol. Chem. 280, 35890-35895.

Van Lenten, B.J., Hama, S.Y., de Beer, F.C., Stafforini, F.C., McIntyre, F.C., Prescott, S.M., La Du, B.N., Fogelman, A.M., and Navab, M. (1995). Anti-inflammatory HDL becomes pro-inflammatory during the acute phase response. Loss of protective effect of HDL against LDL oxidation in aortic wall cell cocultures. J. Clin. Invest. 96, 2758-2767.

Van Lenten, B.J., Navab, M., Shih, D., Fogelman, A.M., and Lusis, A.J. (2001). The role of high-density lipoproteins in oxidation and inflammation. Trends Cardiovasc. Med. 11, 155-161.

Vaziri, N.D., Moradi, H., Pahl, H., Fogelman, A.M., and Navab, M. (2009). In vitro stimulation of HDL anti-inflammatory activity and inhibition of LDL pro-inflammatory activity in the plasma of patients with end-stage renal disease by an Apoa-1 mimetic peptide. Kidney Int. 76, 437-444.

Vedhachalam, C., Chetty, P.S., Nickel, M., Dhanasekaran, P., LundKatz, S., Rothblat, G.H., and Phillips, M.C. (2010). Influence of apolipoprotein (Apo) A-I structure on nascent high density lipoprotein (HDL) particle size distribution. J. Biol. Chem. 285, 31965-31973.

Venkataraman, K., Thangada, S., Michaud, J., Oo, J., Ai, Y., Lee, Y.M., Wu, M., Parikh, N.S., Kahn, F., Proia, R.L., et al. (2006). Extracellular export of sphingosine kinase-1a contributes to the vascular s1p gradient. Biochem. J. 397, 461-471.

Wang, X., Chai, H., Wang, Z., Lin, P.H., Yao, Q., and Chen, C. (2008). Serum amyloid $A$ induces endothelial dysfunction in porcine coronary arteries and human coronary artery endothelial cells. Am. J. Physiol. Heart. Circ. Physiol. 295, H2399-H2408.

Wang, D.X., Liu, H., Yan, L.R., Zhang, Y.P., Guan, X.Y., Xu, Z.M., Jia, Y.H., and Li, Y.S. (2013). The relationship between serum amyloid $A$ and apolipoprotein $A-i$ in high-density lipoprotein isolated from patients with coronary heart disease. Chin. Med. J. (Engl) 126, 3656-3661.

Watson, A.D., Navab, M., Hama, S.Y., Sevanian, A., Prescott, A., Stafforini, A., McIntyre, T.M., Du, B.N., Fogelman, A.M., and Berliner, J.A. (1995a). Effect of platelet activating factor-acetylhydrolase on the formation and action of minimally oxidized low density lipoprotein. J. Clin. Invest. 95, 774-782.

Watson, A.D., Berliner, J.A., Hama, S.Y., La Du, B.N., Faull, K.F., Fogelman, A.M., and Navab, A.M. (1995b). Protective effect of high density lipoprotein associated paraoxonase. Inhibition of the biological activity of minimally oxidized low density lipoprotein. J. Clin. Invest. 96, 2882-2891.

Weichhart, T., Kopecky, C., Kubicek, M., Haidinger, M., Doller, D., Katholnig, K., Suarna, C., Eller, P., Tolle, P., Gerner, P., et al. (2012). Serum amyloid A in uremic HDL promotes inflammation. J. Am. Soc. Nephrol. 23, 934-947.

Wilkerson, B.A., Grass, G.D., Wing, S.B., Argraves, S.B., and Argraves, S.B. (2012). Sphingosine 1-phosphate (S1p) carrierdependent regulation of endothelial barrier: high density lipoprotein (HDL)-s1p prolongs endothelial barrier enhancement as 
compared with albumin-S1P via effects on levels, trafficking, and signaling of S1P1. J. Biol. Chem. 287, 44645-44653.

Witting, P.K., Song, C., Hsu, K., Hua, S., Parry, S.N., Aran, R., Geczy, C., and Freedman, C. (2011). The acute-phase protein serum amyloid $A$ induces endothelial dysfunction that is inhibited by high-density lipoprotein. Free Radic. Biol. Med. 51, 1390-1398.

Xia, P., Vadas, M.A., Rye, M.A., Barter, P.J., and Gamble, P.J. (1999). High density lipoproteins (HDL) interrupt the sphingosine kinase signaling pathway. A possible mechanism for pro- tection against atherosclerosis by HDL. J. Biol. Chem. 274, 33143-33147.

Yamada, T., Kakihara, T., Kamishima, T., Fukuda, T., and Kawai, T. (1996). Both acute phase and constitutive serum amyloid A are present in atherosclerotic lesions. Pathol. Int. 46, 797-800.

Yang, Y., Yan, B., Fu, B., Xu, Y., and Tian, Y. (2005). Relationship between plasma lipid concentrations and HDL subclasses. Clin. Chim. Acta 354, 49-58. 